\title{
Mutations in the SRY, DAX1, SF1 and WNT4 genes in Brazilian sex-reversed patients
}

\footnotetext{
S. Domenice, R.V. Correa,

E.M.F. Costa, M.Y. Nishi,

E. Vilain, I.J.P. Arnhold and B.B. Mendonca
}

\author{
Unidade de Endocrinologia do Desenvolvimento, \\ Laboratório de Hormônios e Genética Molecular (LIM/42), \\ Disciplina de Endocrinologia, Hospital das Clínicas, Faculdade de Medicina, \\ Universidade de São Paulo, São Paulo, SP, Brasil
}

\author{
Correspondence \\ B.B. Mendonca \\ Hospital das Clínicas, FM, USP \\ Av. Dr. Eneas C. Aguiar, 155 \\ PAMB 2o andar, BI. 6 \\ 05403-900 São Paulo, SP \\ Brasil \\ Fax: +55-11-3083-0626 \\ E-mail: beremen@usp.br \\ Presented at the I Symposium on \\ Advances in Medical Research, \\ Institute of Medical Investigation \\ Laboratories, HC-FMUSP, São Paulo, \\ SP, Brazil, March 21-22, 2003. \\ Research partially supported by \\ FAPESP (Nos. 00/06678-9 to \\ R.V. Corrêa, and 00/01737-7 to \\ S. Domenice) and CNPq \\ (No. 301246/95-5 to B.B. Mendonca).
}

Received June 17, 2003

Accepted September 11, 2003

\begin{abstract}
In most mammals, male development is triggered by the transient expression of the $S R Y$ gene, which initiates a cascade of gene interactions ultimately leading to the formation of a testis from the indifferent fetal gonad. Mutation studies have identified several genes essential for early gonadal development. We report here a molecular study of the $S R Y, D A X 1, S F 1$ and WNT4 genes, mainly involved in sexual determination, in Brazilian 46,XX and 46,XY sex-reversed patients. The group of 46,XX sex-reversed patients consisted of thirteen 46,XX true hermaphrodites and four 46,XX males, and was examined for the presence of the $S R Y$ gene and for the loss of function (inactivating mutations and deletions) of DAX1 and WNT4 genes. In the second group consisting of thirty-three $46, X Y$ sex-reversed patients we investigated the presence of inactivating mutations in the SRY and SFI genes as well as the overexpression (duplication) of the DAX1 and WNT4 genes. The SRY gene was present in two 46,XX male patients and in none of the true hermaphrodites. Only one mutation, located outside homeobox domain of the 5' region of the HMG box of SRY (S18N), was identified in a patient with $46, X Y$ sex reversal. A novel 8-bp microdeletion of the $S F 1$ gene was identified in a $46, \mathrm{XY}$ sexreversed patient without adrenal insufficiency. The dosage of $D A X 1$ and WNT4 was normal in the sex-reversed patients studied. We conclude that these genes are rarely involved in the etiology of male gonadal development in sex-reversed patients, a fact suggesting the presence of other genes in the sex determination cascade.
\end{abstract}

Key words

- Sex reversal

- SRY gene

- DAX1 gene

- SF1 gene

-WNT4 gene

\section{Introduction}

The sex-determining gene region of the $\mathrm{Y}$ chromosome (SRY), located on the short arm of the $\mathrm{Y}$ chromosome, has been shown to be the testis-determining factor (1). Genetic evidence supporting this identification came from the observation of 46,XX sex-reversed patients who are carriers of SRY transloca- tions from the $\mathrm{Y}$ to the $\mathrm{X}$ chromosome and of 46,XY sex-reversed patients who harbor mutations in the $S R Y$ gene $(2,3)$. However, the occurrence of sex reversal cannot be explained by $S R Y$ alterations in most of the affected patients. These findings suggest that both "gain of function" and "loss of function" mutations in other genes in the sex determination cascade may cause sex rever- 
sal. Another possibility is that the dosage of critical genes may also affect sex determination. Several autosomal genes (WT1, SF1, SOX9, WNT4, DMRT1-DMRT2) and sexlinked genes (DAXI, ATRX) interact in the process of sex determination, but their exact mechanisms of action are not completely understood $(4,5)$.

The effect of gene dosage on the process of sex determination has been suggested in almost all of its steps. In humans, 46,XX sex reversal is determined by the duplication (overexpression) of SOX9 and by the presence of the $S R Y$ gene $(6,7)$. Duplication of the DAXI and WNT4 genes, as well as haploinsufficiency of the SOX $9, S F 1$, WT1 and DMRT1-DMRT2 genes, have been considered responsible for the development of 46,XY sex reversal (8-14).

We report here the results of the study of genes SRY, DAX1, SF1 and WNT4 in Brazilian 46, $\mathrm{XX}(\mathrm{N}=15)$ and 46, $\mathrm{XY}(\mathrm{N}=33)$ sexreversed patients. Informed consent was obtained from all patients studied according to the criteria established by the Ethics Committee of the Hospital das Clínicas, Faculdade de Medicina, Universidade de São Paulo, São Paulo, SP, Brasil.

\section{SRY gene}

The sex-determining region of the $\mathrm{Y}$ chromosome $(S R Y)$ is located in the distal region of the short arm of the $\mathrm{Y}$ chromosome and is responsible for initiating male sexual determination (15). It consists of a single exon with a central conserved motif, termed HMG box, and has DNA-binding and -bending activities suggesting that $S R Y$ functions as a transcriptional regulator. Mutations in SRY or its flanking regions were identified in several cases of 46,XY sex-reversed patients (complete gonadal dysgenesis, CGD, and partial gonadal dysgenesis, PGD). The frequency of $S R Y$ mutations in $46, \mathrm{XY}$ sexreversed patients was estimated to be $20 \%$ and almost of them induce a CGD (16). We evaluated 7 cases of CGD, 17 of PGD and 9 of embryonic testicular regression syndrome. In a patient with PGD we identified a point mutation at codon $18(\mathrm{~S} 18 \mathrm{~N})$ upstream of the 5' border outside the HMG box of the $S R Y$ gene. This variant sequence was also found in his father and in his normal brother (17). Cases of familial mutations associated with normal fertile males and $46, \mathrm{XY}$ females have been reported $(18,19)$. Incomplete penetrance may be caused by the genetic background, a threshold effect due to altered biochemical properties of the SRY protein. Among these fathers the presence of undetected gonadal mosaicism was determined in rare cases.

The observation of 46,XX sex-reversed patients revealed that some of them carried $S R Y$ translocations from the $\mathrm{Y}$ to the $\mathrm{X}$ chromosome $(3,20)$. XX males can be classified as $\mathrm{Y}$-positive and $\mathrm{Y}$-negative depending on the presence or absence of Y-derived specific sequences. Molecular analyses have demonstrated that approximately $90 \%$ of these patients carry a variable amount of $\mathrm{Y}$ material, including $S R Y$, due to a Y-to-X interchange originated by an illegitimate recombination during paternal meiosis. In XX males with $\mathrm{Y}$-to-X translocation preferential inactivation of the $\mathrm{Y}$-bearing $\mathrm{X}$ chromosome could be the major mechanism causing a sexually ambiguous phenotype (21). Approximately $10 \%$ of $\mathrm{XX}$ males have no detectable $S R Y$ or other Y-sequences. The majority of these patients have ambiguous external genitalia of variable degrees, although a complete male phenotype could be observed. To explain testicular development in the absence of $S R Y$, it has been proposed that a mutation at a normally inactive locus downstream of the $S R Y$, autosomal or X-linked, may confer a gain of function activity to this gene for initiating the testis development pathway. In our experience, the $S R Y$ gene was present in two of four 46,XX males studied. These two patients presented normal male external genitalia. Only one patient 
presented ambiguous external genitalia and was $S R Y$ negative (22).

The majority of XX true hermaphrodites have no cytogenetic evidence for mosaicism, chimerism or translocated $\mathrm{Y}$ chromosome sequences and molecular studies have shown that $S R Y$ and other Y-specific sequences are absent in the great majority of them (20). $S R Y$ was not identified in any of the eleven $46, \mathrm{XX}$ true hermaphrodites of our group (22).

Thus, the $S R Y$ gene is an important factor in the cascade of genetics events necessary for male sex determination, but alone it cannot explain the majority of the sex-reversed cases.

\section{Dosage sensitive sex reversal locus DAX1 gene}

It has been suggested that $S R Y$ represses a negative regulator that normally inhibits testicular development (23). When duplicated, this negative regulator gene may escape $S R Y$ inactivation resulting in absent or incomplete testis development. Supporting this hypothesis, the duplication of the dosage sensitive sex (DSS) reversal locus, a $160-\mathrm{kb}$ region of Xp21.3, was identified in $\mathrm{XY}$ sex-reversed patients (10). The analysis of this locus identified the gene named DAXI (DSS reversal, adrenal hypoplasia congenita on the $\mathrm{X}$ chromosome, gene 1) that encodes a transcriptional repressor factor (24). It has been speculated that the duplication of the $D A X 1$ gene is the cause of gonadal dysgenesis in XY sex-reversed patients in whom the DDS duplication was identified. On the other hand, the presence of loss of function of this gene may prevent the repressor effect on the masculinizing genes and thus determine testicular development in $\mathrm{XX}$ individuals.

$D A X 1$ is expressed in adrenal cortex, gonads, hypothalamus and pituitary (25). It has been speculated that $D A X 1$ might be such a gene (26). To investigate the role of $D A X I$ dosage in the induction of abnormal gonadal development in patients with sex reversal, we searched for the presence of inactivating mutations in $D A X 1$, as well as deletions or extra copies of this gene in patients in whom the $S R Y$ gene was not implicated in the etiology of the disease.

We screened eleven 46,XX true hermaphrodites and two 46,XX males for the presence of inactivating mutations of the DAXI gene and detected no mutations in any of them.

DAXI dosage was determined by the Southern blotting technique with a DAX1specific probe obtained from a PCR product compared to a P450c1alpha probe as an internal control. We analyzed the ratio between the signals of the two probes and compared the values obtained between normal controls and patients. Eleven 46,XX sex-reversed patients were studied to determine the presence of deletions of the DAXI gene.

The results obtained for the patients were similar to those for normal female controls, suggesting the absence of $D A X I$ deletion in this group. Since no inactivating mutations or deletions of $D A X 1$ were identified in these patients, loss of $D A X 1$ function seems not to be involved in the molecular etiology of male gonadal development in these SRYnegative 46,XX sex-reversed patients. In addition, twenty-one 46,XY sex-reversed patients were studied to determine the presence of duplications of the $D A X I$ gene and the results obtained demonstrated the absence of DAXI duplication in this group of patients, ruling out the presence of extra $D A X 1$ copies as the cause of dysgenetic gonads in these patients. Although there is evidence in the literature suggesting that excess expression of $D A X I$ determines the abnormal development of male gonads, no patient with restricted $D A X I$ duplication has been described thus far (27). These data indicate that genetic mechanisms related to the development of dysgenetic gonadal tis- 
sues in patients with DSS locus duplication may be more complex than a simple dosage effect of DAXI.

\section{SF1 gene}

The orphan nuclear receptor steroidogenic factor 1 ( $S F 1$ or NR5A1) is a key regulator of endocrine function within the hypothalamus, pituitary and gonadal axis and adrenal cortex (28). Disruption of the mouse Nr5al gene encoding $S f 1$ causes adrenal and gonadal agenesis, XY sex reversal, structural abnormalities of the ventromedial hypothalamic nucleus and altered gonadotropin expression by the pituitary gonadotrope. Only three mutations in SF1 have been described in humans $(12,29,30)$. In all of these patients, the SF1 mutation caused adrenal insufficiency, and 46,XY sex reversal was detected in two of them. We searched for inactivating mutations in the SFI gene in thirty-two 46,XY sex-reversed patients without adrenal insufficiency. We identified a novel 8-bp microdeletion of the $S F 1$ gene in a 46,XY Brazilian patient with ambiguous genitalia, embryonic testicular regression syndrome and unexpected normal adrenal function. This microdeletion resulted in a premature stop codon at the 378 position determining a loss of function of the SF1 protein.

\section{WNT4 gene}

WNT4 is a member of a large family of WNT signaling glycoprotein molecules. It is involved in gonadal development and hence is also expressed in the developing mesonephros (31). Mouse knockout models have illustrated the primary role of Wnt 4 in female development (14). Mutants of both sexes fail to develop Müllerian ducts, and Wolffian ducts are stabilized in the female null mutant because of differentiation of Leydig-like interstitial cells in the ovary. Wnt4 appears to prevent Leydig cell differentiation in the ovary. The expression of Wnt4 is similar to
D a $x 1$, suggesting that Wnt4 may function in a similar manner as an anti-testis gene. A 46,XY sex-reversed patient with duplication of 1p31-p35, in whom WNT4 was overexpressed (32) was reported, suggesting an effect of WNT4 gene dosage on the steps of human sex determination. It was proposed that the mechanism of sex reversal was via WNT4 induced up-regulation of DAXI.

To investigate the role of WNT4 dosage in the induction of abnormal gonadal development in patients with sex reversal, we searched for the presence of inactivating mutations in WNT4 as well as deletions or extra copies of this gene in sex-reversed patients. We screened for the presence of inactivating mutations of the WNT4 gene in eleven 46,XX true hermaphrodites and two $46, \mathrm{XX}$ males and detected no mutations in any of these patients.

The search for WNT4 dosage was performed using the Southern blotting technique with a WNT4-specific probe obtained from a PCR product compared with a DAX1 probe, as an internal control. We analyzed the ratio between the signals of the two probes and compared the values obtained for the normal controls and patients. We studied thirteen 46,XX sex-reversed patients to determine the presence of deletions of the WNT4 gene and twenty-one 46,XY sex-reversed patients to determine the presence of duplications of this gene. The results obtained for the patients were similar to those obtained for normal controls, suggesting the absence of abnormal WNT4 dosage in both groups of patients (Domenice S, Corrêa RV and Mendonca BB, unpublished data). No inactivating mutations of WNT4 were identified in 46,XX patients (Domenice S, Corrêa RV and Mendonca BB, unpublished data). These results demonstrate the absence of abnormalities of the WNT4 gene in these sexreversed patients.

Over the past few years, considerable progress has been made in the molecular characterization of sex reversal disorders by 
using a combination of strategies such as cell biology and animal models and especially by studying patients with these disorders. The majority of the key regulatory steps in fetal sex development relevant to clinical investigation were studied here and they may be responsible for a minority of the sex-reversed cases. Although genetic analyses have suggested that gene dosage appears to be important in human sexual development, we did not identify any abnormality in two important genes, DAXI and WNT4, related to the development of dysgenetic gonads.

We conclude that the $S R Y, D A X 1, S F 1$ and WNT4 genes are rarely involved in the etiology of male gonadal development in sex-reversed patients (Table 1), a fact suggesting the involvement of other genes in the sexual determination cascade.
Table 1. Molecular findings of SRY, DAX1, SF1 and WNT4 genes in Brazilian sexreversed patients.

\begin{tabular}{lcccc}
\hline Sex reversed & Gene & Molecular finding & Patients* & Diagnosis \\
\hline $46, \mathrm{XX}$ & SRY & SRY+ & $2 / 15$ & XX male \\
& DAX1 & No mutations & $0 / 13$ & - \\
& Normal gene dosage & & - \\
& WN1 & Not studied & - & - \\
& No mutations & $0 / 13$ & \\
$46, \mathrm{XY}$ & Normal gene dosage & & PGD \\
& SRY & S18N & $1 / 33$ & - \\
& DAX1 & Not studied & - & ETRS \\
& SF1 & Del 8nt 1058-1065 & $1 / 32$ & - \\
\hline
\end{tabular}

ETRS = embryonic testicular regression syndrome; PDG = partial gonadal dysgenesis. *Number of patients with molecular alterations/total number of studied patients.

\section{References}

1. Berta P, Hawkins JR, Sinclair AH, Taylor A, Griffths BL, Goodfellow PN \& Fellous M (1990). Genetic evidence equating SRY and the testis determinig factor. Nature, 348: 448-450.

2. Vilain E, McElreavey K, Vidaud M, Richaud F \& Fellous M (1991) L'analyse de SRY n'explique pas toute la pathologie du determinisme du sexe. Annales d'Endocrinologie, 52: 435-436.

3. Fechner PY, Marcantonio SM, Jaswaney V, Stetten G, Goodfelow PN, Migeon CJ, Smith KD \& Berkovitz GD (1993). The role of the sex-determining region $Y$ gene in the etiology of $46, X X$ maleness. Journal of Clinical Endocrinology and Metabolism, 76: 690-695.

4. Veitia RA, Salas-Cortés L, Ottolenghi C, Pailhoux E, Cotinot C \& Fellous $M$ (2001). Testis determination in mammals: more questions than answers. Molecular and Cellular Endocrinology, 179: 316.

5. Ahmed SF \& Hughest IA (2002). The genetics of male undermasculinization. Clinical Endocrinology, 56: 1-18.

6. Boucekkine C, Toublanc JE, Abbas N et al. (1994). Clinical and anatomical spectrum in $X X$ sex reversed patients. Relationship to the presence of $Y$ specific DNA-sequences. Clinical Endocrinology, 40: 733-742

7. Huang B, Wang S, Ning Y, Lamb AN \& Bartley J (1999). Autosomal $X X$ sex reversal caused by duplication of SOX9. American Journal of Medical Genetics, 87: 349-353.

8. Pelletier J, Bruening W, Li FP, Glaser T, Harber DA \& Housman D (1991). WT1 mutations contribute to abnormal genital system development and hereditary Wilm's tumor. Nature, 353: 431-434.

9. Hawkins JR, Taylor A, Berta P, Levilliers J, Van der Auwera B \& Goodfellow PN (1992). Mutational analysis of SRY: nonsense and missense mutations in XY sex reversal. Human Genetics, 88: 471474.

10. Bardoni B, Zanaria E, Guioli S et al. (1994). A dosage sensitive locus at chromosome Xp21 is involved in male to female sex reversal.
Nature Genetics, 7: 497-501.

11. Foster JW, Dominguez-Steglich MA, Guioli S et al. (1994). Campomelic dysplasia and autosomal sex reversal caused by mutations in an SRY-related gene. Nature, 372: 525-529.

12. Achermann JC, Ito M, Ito M, Hindmarsh PC \& Jameson JL (1999). A mutation in the gene encoding steroidogenic factor 1 causes $X Y$ sex reversal and adrenal failure in humans. Nature Genetics, 22: 125126 (Letter).

13. Raymond CS, Parker ED, Kettlewell JR et al. (1999). A region of human chromosome $9 p$ required for testis development contains two genes related to known sexual regulators. Human Molecular Genetics, 8: 989-996.

14. Vainio S, Heikkila M, Kispert A, Chin N \& McMahon AP (1999). Female development in mammals is regulated by Wnt-4 signalling. Nature, 397: 405-409.

15. Sinclair AH, Berta P, Palmer MS, Hawkins JR, Griffiths BL, Smith MJ, Foster JW, Frischauf AM, Lovell-Badge R \& Goodfellow PN (1990). A gene from the human sex-determining region encodes a protein with homology to a conserved DNA-binding motif. Nature, 346: $240-246$.

16. Hawkins JR, Taylor A, Goodfellow PN, Migeon CJ, Smith KD \& Berkovitz GD (1992). Evidence for increased prevalence of SRY mutations in $X Y$ females with complete rather than partial gonadal dysgenesis. American Journal of Human Genetics, 51: 979-984.

17. Domenice S, Nishi MY, Billerbeck AEC et al. (1998). A novel missense mutation (S18N) in the 5'non-HMG box region of SRY gene in a patient with partial gonadal dysgenesis and his normal male relatives. Human Genetics, 102: 213-215.

18. Jäger RJ, Harley VR, Pfeiffer RA, Goodfellow PN \& Scherrer GA (1992). A familial mutation in the sex determining gene SRY shared by both sexes. Human Genetics, 90: 350-355.

19. Vilain E, McElreavey K, Jaubert F, Raymond JP, Richaud F \& Fellous 
M (1992). Familial case with sequence variant in the testis determining region associated with two sex phenotypes. American Journal of Human Genetics, 50: 1008-1011.

20. Zenteno-Ruiz JC, Kofman-Alfaro S \& Mendez JP (2001). 46,XX sex reversal. Archives of Medical Research, 32: 559-566.

21. Kusz K, Kotecki M, Wodja A, Szarras-Czapnik M, Latos-Bielenska A, Warenik-Szymankiewiccs A, Ruszczynska-Wolska A \& Jaruzelska J (1999). Incomplete masculinization of XX subjects carrying the SRY gene on an inactive $X$ chromosome. Journal of Medical Genetics, 36: 452-456.

22. Domenice S, Nishi MY, Billerbeck AEC, Carvalho FM, Frade EMC, Latronico AC, Arnhold IJP \& Mendonca BB (2001). Molecular analysis of SRY gene in Brazilian 46,XX sex-reversed patients: absence of SRY sequence in gonadal tissue. Medical Science Monitor (http:// www.msi.com.pl), 7: 238-241.

23. McElreavey K, Vilain E, Abbas N, Herskowitz I \& Fellous M (1993). A regulatory cascade hypothesis for mammalian sex determination: SRY represses a negative regulator of male development. Proceedings of the National Academy of Sciences, USA, 90: 3368-3372.

24. Guo W, Burris TP, Zhang YH, Huang BL, Mason J, Copeland KC, Kupfer SR, Pagon RA \& McCabe ERB (1996). Genomic sequence of the DAX-1 gene: An orphan nuclear receptor responsible for $\mathrm{X}$ linked adrenal hypoplasia congenita and hypogonadotropic hypogonadism. Journal of Clinical Endocrinology and Metabolism, 81: 24812486.

25. Yu RN, Achermann JC, Ito M \& Jameson JL (1998). The role of DAX1 in reproduction. Trends of Endocrinology and Metabolism, 9: 169-
175.

26. Kolon TF, Ferrer FA \& McKenna PH (1998). Clinical and molecular analysis of XX sex reversed patients. Journal of Urology, 160: 11691172.

27. Swain A, Narvaez V, Burgoyne P, Camerino G \& Lovell-Badge R (1998). Dax1 antagonizes Sry action in mammalian sex determination. Nature, 391: 761-767.

28. Parker KL \& Schimmer BP (1997). Steroidogenic factor 1: a key determinant of endocrine development and function. Endocrine Reviews, 18: 361-377.

29. Biason-Lauber A \& Schoenle EJ (2000). Apparently normal ovarian differentiation in a prepubertal girl with transcriptionally inactive steroidogenic factor 1 (NR5A1/SF1) and adrenocortical insufficiency. American Journal of Human Genetics, 67: 1563-1568.

30. Achermann JC, Ozisik G, Ito M, Orun UA, Harmanci K, Gurakan B \& Jameson JL (2002). Gonadal determination and adrenal development are regulated by the orphan nuclear receptor steroidogenic factor-1, in a dose-dependent manner. Journal of Clinical Endocrinology and Metabolism 87: 1829-1833.

31. Stark K, Vainio S, Vassileva G \& McMahon AP (1994). Epithelial transformation of metanephric mesenchyme in the developing kidney regulated by Wnt4. Nature, 372: 679-683.

32. Jordan BK, Mohammed M, Ching ST, Delot E, Chen XN, Dewing $P$, Swain A, Rao N, Elejalde BR \& Vilain E (2001). Up regulation of WNT4 signaling and dosage sensitive sex reversal in humans. American Journal of Human Genetics, 68: 1102-1109. 